\title{
A educação artística no trilho de uma nova cidadania
}

\section{Artistic education on the path of a new citizenship}

\author{
Mónica Oliveira \\ Centro de Estudos em Desenvolvimento Humano, Universidade Católica Portuguesa, Escola Superior de Educação Paula Frassinetti, \\ Instituto de Investigação em Arte, Design e Sociedade da UP
}

\begin{abstract}
Resumo
$\mathrm{O}$ artigo resulta de um projeto de investigação centrado na necessidade de equacionar a educação artística, mais concretamente a arte contemporânea, na promoção de uma cultura de cidadania no $1 .{ }^{\circ}$ Ciclo do Ensino Básico $\left(1 .^{\circ} \mathrm{CEB}\right)$. Este trabalho privilegia uma investigação qualitativa e foi ao encontro dos seguintes objetivos: implementar um conjunto de atividades pedagógicas assentes na arte contemporânea no $1 .^{\circ} \mathrm{CEB}$ e compreender o seu impacto na aprendizagem dos alunos e na prática profissional dos professores. As conclusões emergentes do estudo evidenciam a importância da arte contemporânea no desenvolvimento de competências que visam a construção de uma cidadania ativa.

Palavras-chave: educação artística, arte contemporânea, cidadania, $1 .^{\circ}$ ciclo do ensino básico.
\end{abstract}

\begin{abstract}
The article results from a research project focused on the need to equate artistic education, more specifically contemporary art, in promoting a culture of citizenship in the 1st Cycle of Basic Education (1st CEB). This work focuses on qualitative research and has met the following objectives: To implement a set of pedagogical activities based on contemporary art in the 1st CEB and to understand its impact on student learning and professional practice of teachers. The emerging conclusions of the study highlight the importance of contemporary art in the development of skills that aim to build active citizenship. Keywords: artistic education, contemporary art, citizenship, 1st cycle of basic education
\end{abstract}

Vivemos num mundo que é cada vez mais multicultural e heterogéneo, onde as transformações socioculturais são mais rápidas e também mais assustadoras: se por um lado acolhemos a diversidade cultural, por outro lado surge a divisão e a polémica. As divergências, as clivagens e os confrontos de opinião, agitam a nossa sociedade.

Percebemos que os valores morais vão-se alterando ou mesmo desaparecendo; que as tecnologias de informação acenam-nos com diversas soluções, todas elas diferentes e aparentemente ilimitadas, mas efémeras e por vezes perversas; agudizam-se formas de intolerância e violência; convivemos com a exclusão social de indivíduos e grupos sociais e não possuímos certezas e soluções para enfrentar e resolver os diferentes problemas, restando-nos apenas a incerteza do momento presente e a esperança de uma nova realidade.

Este panorama leva-nos a questionar que tipo de educação preconizamos para que os nossos alunos se possam constituir cidadãos capazes de perceber e intervir no mundo de forma responsável e operar uma transformação social consciente.

E é nesta certeza que a educação é chamada a intervir, assumindo os desafios necessários à construção de uma nova cidadania e assumindo um compromisso com a formação e a educação integral do ser humano que ajude as novas gerações a construírem, de uma forma autónoma, uma forma de pensar, sentir, querer e atuar (Conill, 2002), proporcionando aos alunos uma inserção responsável através da convocação de temas reais que traduzem as preocupações atuais. Na verdade trata-se de falar de cidadania, ou melhor, de educar para a cidadania. A cidadania depende cada vez mais da educação já que é através dela que se veiculam conhecimentos e saberes, atitudes, valores e normas sociais (Martins e Mogarro, 2010; Damião, 2005; Ross, 2004, 2008), com o objetivo de preparar os alunos para se adaptarem melhor à complexidade dos processos e dinâmicas envolvidas na vivência cidadã e às rápidas mudanças de um mundo cada vez mais interdependente, globalizado e menos seguro e, assim, se desenhar um mundo melhor.

E, desde logo, uma questão se levanta: de que forma o contacto com a educação artística, especificamente com a arte contemporânea, poderá ampliar horizontes, consciências críticas e potenciar a construção de uma cidadania ativa nos alunos no $1 .^{\circ}$ Ciclo do Ensino Básico $\left(1 .^{\circ} \mathrm{CEB}\right)$ ?

Sendo a escola o espaço privilegiado para formar cidadãos ativos, torna-se fundamental que espelhe a nossa cultura e o nosso património artístico, expressão máxima da natureza humana. Uma sociedade contemporânea e desenvolvida, uma sociedade inclusiva e participada, necessita de cidadãos culturalmente desenvolvidos e ideologicamente preparados. Pensar a arte na educação é compreender a importância das artes ao nível dos processos e mecanismos de construção de conhecimento e entendimento sobre o mundo e sobre a existência. Como afirma Buoro, “(...) a finalidade da Arte na educação é propiciar uma relação consciente do 
ser humano no mundo e para o mundo, contribuindo na formação de indivíduos mais críticos e criativos que, no futuro, atuarão na transformação da sociedade." (1988, p.33)

E a arte contemporânea, caraterizada por uma forte componente estética e ética, acompanha em tempo real a nossa vida, documentando a história que estamos presentemente a viver. Ela atualiza e dá visibilidade a acontecimentos, a preocupações, "ousando" chamar a atenção do público para o mundo real, num relato aberto a múltiplas interpretações, promovendo uma maior integração entre as manifestações artísticas e as experiências vitais.

Parte das expetativas depositadas pela sociedade na educação relacionam-se com a tentativa de encontrar soluções para os desafios e os problemas no contexto da contemporaneidade. A educação artística, através da arte contemporânea, inscreve-se neste âmbito orientador pelas suas potencialidades educativas, particularmente ao nível da mobilização e desenvolvimento de competências na construção de indivíduos e sociedades mais críticos e criativos, com respeito pela diversidade, preparando-os para enfrentar novos desafios com um olhar inovador, contribuindo para $\mathrm{o}$ avanço das sociedades. Ao estabelecermos pontes com o mundo artístico atual seremos capazes de formar pessoas que possam construir o seu corpo de conhecimentos tendo por base a época em que vivem.

O convite para pensar sobre arte na atualidade, seja através da reflexão, da perceção e até mesmo pela via do "estranhamento", propõe enfrentarmos o novo, o diferente, que de uma maneira ou de outra nos interpela, nos aguça a curiosidade, agita a nossa afetividade e, muitas vezes, nos incomoda. Refletir sobre imagens, obras de arte, objetos artísticos, é colocar à disposição dos alunos um conjunto de conhecimentos que lhes permita abrir os seus referenciais artísticos que resultem em aprendizagens (trans)formadoras no âmbito da promoção de uma cidadania ativa.

Neste projeto A Educação Artística no trilho de uma nova Cidadania, procurou-se desenhar um conjunto de atividades artísticas, centradas na arte contemporânea, que visam a promoção de uma cultura de cidadania no 1. ${ }^{\circ}$ Ciclo do Ensino Básico, pensando-se o mundo atual para nele se intervir (Canário, 2005) indo ao encontro dos seguintes objetivos: i) Conceber e implementar atividades de educação artística para a cidadania; ii) Compreender o impacto das atividades na aprendizagem dos alunos e na prática profissional dos professores.

A orientação metodológica deste trabalho enquadra-se numa abordagem de natureza qualitativa, uma vez que o objetivo do estudo se prende com o interesse em conhecer e descrever a implementação e impacto de atividades práticas e conceções pessoais sobre a prática pedagógica, ou seja, “(...) compreender o processo mediante o qual as pessoas constroem significados e descrever em que consistem estes mesmos significados." (Bogdan \& Biklen, 1994, p.70). Assim, este é um estudo descritivo, analítico e interpretativo.

\section{Método}

\section{Participantes}

A população alvo deste estudo é constituída por 676 alunos do $1 .^{\circ} \mathrm{CEB}$, o que corresponde a 32 turmas de 19 escolas do distrito do Porto. Da amostra recolhida, 20 instituições são de Ensino Particular e 12 de Ensino Público. A implementação das atividades envolveu ainda 32 professores, cuja maioria possuí idades compreendidas entre os 42 os 47 anos. Em termos de habilitações, $68,7 \%$ dos professores, é detentor do grau de mestre e $31,2 \%$ possuí o grau de licenciado.

\section{Procedimentos}

Este projeto iniciou-se com 2 ações de formação com a duração de 50 horas presenciais. Cada uma delas teve 16 professores inscritos. As primeiras 2 sessões foram dedicadas ao aprofundamento das temáticas relativas à cidadania e à educação artística, mais concretamente à arte contemporânea. Seguidamente, o enfoque da ação passou pela questão didática indo ao encontro dos pressupostos pedagógicos orientadores do projeto. Terminada esta fase de enquadramento, as sessões seguintes foram dedicadas à apresentação dos diferentes temas e diferentes planificações das atividades artísticas a realizar com os alunos. A programação proposta estava dividida em diferentes temáticas: $\mathrm{O}$ meu lugar no mundo; Eu e os outros; A minha família; Somos todos diferentes; Em busca da vida saudável e Eu.comunicao.@.pt. Estas atividades centraram a sua atenção: nos princípios e valores orientadores enunciados no Currículo Nacional do Ensino Básico; em competências cognitivas, éticas e de valores e, por último, sociais; numa metodologia centrada no trabalho por projetos; na investigação e na interdisciplinaridade.

Entre as sessões presenciais, os professores implementavam as atividades na sua turma. No início de cada sessão, cada professor apresentava o trabalho realizado com os alunos e uma breve reflexão sobre o mesmo. Esta reflexão pretendia ir ao encontro de uma análise da situação vivenciada, apontando os constrangimentos e as potencialidades educativas observadas. Os materiais, que suportaram a exploração das diferentes atividades, foram-lhes disponibilizados no decorrer da ação de formação pela formadora (investigadora).

\section{Técnicas de recolha de dados}

A recolha de dados foi realizada através de uma narrativa escrita por cada professor que participou da ação de formação. Evitou-se desenhar linhas orientadoras para a construção da narrativa individual, porém, solicitou-se aos professores que ponderassem sobre a implementação e o impacto das atividades nos alunos e na sua prática profissional. A opção por este tipo de investigação prende-se com o facto de as narrativas nos oferecerem relatos de pessoas em situações reais, confrontando-se com questões reais, permitindo-nos aceder à complexidade das interpretações que estas fazem das suas vivências (Chamberlayne, Bornat e Wengraf, 2000), das suas ações, dos seus sucessos, dos problemas, dos desafios e 
dilemas com os quais são confrontados. No caso específico, permite-nos analisar a prática do professor, já que fornece elementos para compreender o pensamento do seu autor, o significado que atribui à sua prática pedagógica (Connelly e Clandinin, 1990), aos modos de atuar, assim como compreender os contextos em que se desenrolaram as ações, dando uma informação situada e avaliada do que se está a investigar.

\section{Resultados}

Apresentam-se de seguida e de forma resumida os principais resultados obtidos. A análise dos resultados fez emergir várias categorias e subcategorias de conteúdo, dos quais se destacam as seguintes:

\section{Impacto das atividades no ensino-aprendizagem dos alunos.}

Desta categoria emergem as seguintes subcategorias: Empenho e motivação na realização das atividades propostas; Aquisição de novos conhecimentos; Desenvolvimento de competências estipuladas.

\section{Empenho e motivação na realização das atividades propostas.}

Todos os professores manifestaram que existiu um grande envolvimento e motivação dos alunos nas atividades. Esta razão deve-se, no entender de $80 \%$ dos professores, ao caráter inovador das atividades, mais concretamente: "ao título e texto da proposta que geraram grande interesse e curiosidade" (P6); "aos temas relacionados com a vida dos alunos”(P16); “à visualização de imagens de artistas e obras" (P20).

Também foram salientadas por $70 \%$ dos docentes a importância das estratégias pedagógicas serem ativas e colaborativas: "os alunos trabalharam em projetos"(P24) "foram os construtores da sua própria aprendizagem" (P9); "Cada aluno foi importante para a construção da atividade"(P12).

$50 \%$ dos professores entenderam que a reação positiva por parte dos alunos surgiu do caráter lúdico e holístico, caraterísticas a que subjazem as atividades como referem os seguintes testemunhos: "os alunos a brincar, formaram conceitos, selecionaram ideias, estabeleceram relações lógicas (...)" (P13); "envolverem-se de forma intensa e total, numa atividade criando um clima de entusiasmo"(P7).

\section{Aquisição de novos conhecimentos.}

Todos os professores afirmaram que as atividades permitiram aos alunos a aquisição de novos conhecimentos.

90\% dos professores realçaram que as atividades permitiram aos alunos obter mais informação sobre o contexto atual da sociedade: "os problemas do bairro onde viviam eram muitas vezes expressos nas atividades" (P31); "os alunos discutiam as notícias do telejornal” (P33).
$85 \%$ dos docentes afirmaram que os alunos adquiriram conhecimentos sobre arte, artistas e técnicas: "a instalação artística é a forma de arte mais interessante"(P7); "os artistas falam da vida como se fossem jornalistas" (P5); "a artista utilizou esta técnica para dar sentido à sua ideia”(P31) .

\section{Desenvolvimento de competências.}

Os professores realçaram a importância de terem sido trabalhadas competências específicas e transversais no decorrer das atividades, importantes para o desenvolvimento de uma cidadania ativa através da literacia artística. 90\% dos professores referenciaram várias competências específicas relacionadas com a compreensão das artes no contexto, com a expressão e comunicação e com a criatividade como atestam os seguintes testemunhos: "valorizaram a cultura da sua cidade"(P10); "apreciaram obras artísticas"(P4); "trabalharam várias técnicas artísticas"(P3); "a sua representação gráfica mostrava muito sobre a sua forma de pensar e ser" (P19); "eram recetivos a diferentes formas de expressão artística" (P15); "encontravam soluções originais para colocar em prática” (P13).

Também foram mencionadas por $85 \%$ dos professores, competências transversais das quais se destacam a autoestima e a autoconfiança, a relação interpessoal e cívica e o pensamento crítico como se pode constatar nas seguintes opiniões: "Os alunos tornaram-se mais desinibidos" (P8), "ganharam confiança na forma de pensar e criar" (P15); "mantiveram uma relação de respeito e de interajuda entre os colegas" (P12);"começaram a respeitar a arte e os artistas atuais através da relação que estabeleceram com os seus trabalhos" (P16); "debateram diversas questões sobre os temas da sociedade relacionando-os com a arte" (P5).

\section{Impacto das atividades na prática profissional dos professores.}

Desta categoria emergem duas subcategorias: Aquisição de novos conhecimentos e Introdução de modificações na sua prática educativa.

Aquisição de novos conhecimentos

$90 \%$ realçaram que perceber as diversas intencionalidades artísticas associadas ao trabalho criativo dos artistas, as suas obras, bem como, as técnicas e materiais apresentados ampliou os seus conhecimentos específicos da área artística: "nunca imaginei a quantidade de materiais e de técnicas em que as obras se podiam concretizar"(P4); "conhecer artistas de diversas áreas desde a arte urbana, à escultura, passando pela instalação até ao desenho, foi um universo fantástico que se abriu para mim" (P8); "é fundamental conhecer e participar da nossa cultura artística" (P26). Mais acrescentaram que "estes novos conhecimentos advieram do material didático sugerido pela investigadora nas atividades (referências a artistas, ligações a sites e vídeos)"(P6), fundamental para perceberem como e onde investigar, gerando novo conhecimento e interesse em propor novas atividades. 
$80 \%$ dos interlocutores realçaram que as propostas de atividades apresentadas permitiram-lhes conhecer melhor as intencionalidades pedagógicas que as subjazem: "graças aos objetivos e conteúdos elencados nas atividades percebi o verdadeiro interesse pedagógico desta área"(P6); “esta área é fundamental para a consciencialização do conhecimento de outras áreas do saber"(P7); "permite o desenvolvimento de competências essenciais à formação dos alunos" (P5).

\section{Introdução de modificações na sua prática educativa.}

$80 \%$ dos interlocutores assumiram que introduziram atividades didáticas centradas na inovação e numa intencionalidade educativa capazes de formar cidadãos culturalmente evoluídos: "proponho atividades artísticas que articulem teoria e prática, ligadas a questões sociais e culturais do mundo atual" (P17). "hoje concebo atividades que visem rasgar os horizontes culturais dos alunos" (P4).

$80 \%$ dos professores realçou a importância de utilizar novos recursos pedagógicos diferenciadores na implementação da prática educativa: "os recursos didáticos têm a capacidade de despertar e estimular a criatividade do aluno"(P24); "eles aumentam e melhoram o entendimento dos alunos em relação ao assunto trabalhado" (P14).

$75 \%$ dos docentes afirmou que a investigação passou a fazer parte da sua estratégia educativa: "atualmente, tenho necessidade de me atualizar buscando sempre referências a autores, artistas para suportar os conteúdos lecionados" (P9); "atualizome sempre sobre aspetos artísticos e pedagógicos do currículo"(P10).

\section{Discussão dos dados}

Os resultados analisados através das narrativas dos professores foram muito positivos. Fortemente marcadas por uma ampla recetividade das atividades artísticas por parte dos seus interlocutores, as propostas foram consideradas úteis e eficazes na promoção de oportunidades de aprendizagem e no desenvolvimento das competências adequadas que concorrem para a construção de uma nova cidadania. A experiência artística atual nestas atividades converteu-se em relato social, revelando-se um espaço para a análise de questões sociais, permitindo aceder a leituras da vida humana. Esta situação vai ao encontro do que afirmam Guimarães e Neves (2013) apontando para a relevância das expressões artísticas na (re)construção e (re)descoberta de identidades e no desenvolvimento de uma consciência participativa nas sociedades contemporâneas.

A intervenção educativa pela arte fomentou processos de mudança nos alunos já que existem referências a transformações do ponto de vista social, cultural, emocional, cognitivo e estético. Esta situação verificou-se na implementação das atividades propostas com novas estratégias pedagógicas, para fazer face às exigências do tempo em que vivemos, indo ao encontro de novas formas de ensino-aprendizagem "que ativem os interesses dos alunos e promovam aprendizagens significativas e projetos de vida saudáveis." (Palmeirão, 2015, p.35). Também o aspeto lúdico foi considerado. Como afirma Santos "facilita a aprendizagem, o desenvolvimento pessoal, social e cultural (...) facilita os processos de socialização comunicação, expressão e construção do conhecimento" (1997, p. 12), ou seja, possibilita um fortalecimento da relação entre o que se ensina e o que se aprende (Roloff, 2010). A dimensão interdisciplinar tornou-se fundamental pois nunca foi encarada como um conhecimento constituído de várias áreas do saber combinadas por lógicas aditivas, mas houve, na construção das atividades, uma transformação do saber, passando a constituir-se como parte integrante uns dos outros. (Roldão, 2007). Por último, é legítimo considerar que as práticas artísticas, como um meio incontornável no desenvolvimento de competências, nomeadamente ao nível da expressão e comunicação, criatividade, compreensão das artes no contexto, relação interpessoal e cívica, pensamento crítico e reflexivo, exploraram diferentes possibilidades educativas da "cidade" e da sociedade. (Nóvoa, 2017).

Também os professores que implementaram estas atividades não lhes ficaram indiferentes, atestando a aprendizagem de novos conhecimentos, novos conteúdos sobre a área artística, os princípios da sua organização concetual e o modo de problematizá-los (Shulman, 2005), entendendo-a como "um ato de conhecimento, uma aproximação crítica da realidade." (Freire, 1979, p.25). Utilizando para tal recursos pedagógicos diferenciadores como material de auxílio no ensino-aprendizagem do conteúdo proposto para ser aplicado aos alunos.

Estes materiais (imagens/vídeos, etc.) tiveram como objetivo suscitar motivação pois rompem com a rotina, conferiram aos alunos condições para aprenderem conceitos, desenvolverem habilidades, competências e atitudes e representam uma oportunidade de olhar o mundo e confrontar o aprendido com a realidade (Brandimonte, 2003; Cavalcante e Silva, 2008). Desta forma os professores desenvolveram atitudes e capacidades de reflexão de forma autónoma e crítica que lhes permitiu desenvolver $\mathrm{o}$ seu potencial de pesquisa/investigação sobre a sua própria prática profissional e tomar decisões pedagógicas (Pereira, 2011), organizando a aula de forma consciente, criativa e capaz de produzir um efeito positivo na aprendizagem do aluno (Negri, 2008) e incorporar práticas inovadoras com vista à mudança educativa.

Deste modo, este projeto, apesar das suas limitações, quer no que diz respeito ao reduzido tempo de intervenção, quer no que respeita ao número de participantes, alvitra novos trilhos de intervenção ao nível das práticas artísticas e de uma cidadania inclusiva, respeitadora e integradora das 
diferentes identidades, consentânea com o mundo em que vivemos.

A implementação destas atividades mostrou que é possível e desejável que, a partir da educação artística, concretamente da arte contemporânea, os professores introduzam propostas didáticas que contribuam para a construção de uma nova cidadania.

\section{Referências}

Bogdan, R. \& Bilken, S. (1994). Investigação Qualitativa em Educação. Porto: Porto Editora.

Brandimonte, G. (2003). El soporte audiovisual en la clase de E/EL: El cine y la televisión. Actas XIV Congreso Internacional de ASELE (pp. 870-881). Burgos: Centro Virtual Cervantes. http://cvc.cervantes.es/ensenanza/biblioteca_ele/asele/ pdf/14/14_0871.pdf.

Buoro, A. (1998). O olhar em construção: uma experiência de ensino e aprendizagem da arte na escola. São Paulo: Cortez.

Canário, R. (2005). O que é a Escola? - Um "olhar" sociológico. Porto: Porto Editora.

Cavalcante, D.; Silva, A. (2008). Modelos didáticos e professores: concepções de ensino-aprendizagem e experimentações. Atas do XIV Encontro Nacional de Ensino de Química,(pp.100-115). Curitiba: UFPR. http://www.quimica.ufpr.br/eduquim/eneq2008/resum os/R0519-1.pdf

Chamberlayne, P., Bornat, J. \& Wengraf, T. (Eds.) (2000). The Turn to Biographical Methods in Social Science: Comparative Issues and Examples. London: Routledge.

Connelly, M. \& Cladinin, J. (1990). On narrative method, personal philosophy, and narrative unities in the story of teaching. Journal of Research in Science Teaching, 23, 293-310. http://dx.doi.org/10.1002/tea.3660230404

Conill, J. (2002). Educar en la ciudadanía. Valência: Instituciò Alfons el Magnánim.

Damião, H. (2005). Educação para a cidadania no Ensino Básico: Análise de documentos curriculares vigentes. In C. Vieira, A. Seixas, M. Lima, M. Vilar \& M. Pinheiro (Eds.), Ensaios sobrtamento humanoDo Diagnóstico à Intervenção. (pp. 327-341). Coimbra: Almedina.

Freire, P. (1979). Conscientização: teoria e prática da libertação. São Paulo: Cortez/Moraes.

Guimarães, J. \& Neves, T. (2013). A Comunidade Dança? Reflexão sobre projetos de intervenção artística em contextos rurais. Educação, Sociedade e Culturas.

$$
40 \text {, }
$$
147-163. http://www.fpce.up.pt/ciie/sites/default/files/ESC40_J _Guimaraes_T_Neves.pdf

Martins J.\& Mogarro M. (2010). A educação para a cidadania no século XXI. Revista Iberoamericana de educación, 53,185-202.

http://hdl.handle.net/10451/12314

Pereira, C. (2011). O papel da investigação na formação de Educadores e Professores - Um estudo de caso.
Nuances: estudos sobre Educação, 20, 80-98. http://dx.doi.org/10.14572/nuances.v20i21.1098

Negri, P. (2008). Comunicação Didática: A Intencionalidade Pedagógica como Estratégia de Ensino. Módulo I. Londrina: Labted/ Uel.

Nóvoa, A. (2017). Prefácio. In P. Morais (Ed.) Voltemos à Escola - Como a Escola da Ponte ensina de forma diferente há 40 anos. Lisboa: Contraponto.

Palmeirão, C. (2015). Assessoria pedagógica - Um projeto formativo para a melhoria. In J. Machado, M. Alves (Orgs). Professsores, Escola e Município Formar, Conhecer e Desenvolver (pp.33-41). Porto: Universidade Católica Editora.

Roldão, M. (2007). Função docente: natureza e construção do conhecimento profissional. Revista Brasileira de Educação,12, 94-181. http://www.scielo.br/pdf/rbedu/v12n34/a08v1234.pdf

Roloff. E. (2010). A importância do lúdico em sala de aula. Semana de Letras, 10, (pp.1-9) Porto Alegre: Edipucrs.

http://ebooks.pucrs.br/edipucrs/anais/Xsemanadeletra s/comunicacoes/Eleana-Margarete-Roloff.pdf

Ross, A. (2004). Desiderius Erasmus and the Experience of Citizenship Today. In A. Ross (Ed.) The experience of Citizenship (pp.3-26). London: CiCe publication.

Ross, A. (2008). Education for Citizenship Society and Identity: Europe and its Regions. Atas Educação para a Cidadania: Conferência Ibérica (pp.1-10). Lisboa: Faculdade de Ciências da Universidade de Lisboa.

Santos, M. (1997). O lúdico na formação do Educador. Petrópolis, RJ: Vozes.

Shulman, L. (2005). El saber y entender de la profesión docente. Estúdios Públicos, 99, 195-224. 